\title{
Surface water flood risk and management strategies for London: An Agent-Based Model approach
}

\author{
Katie Jenkins ${ }^{1, a}$, Swenja Surminski ${ }^{2}$, Jim Hall ${ }^{1}$, and Florence Crick $^{2}$ \\ ${ }^{1}$ Environmental Change Institute (ECI), University of Oxford, South Parks Road, Oxford, OX1 3QY, UK \\ ${ }_{2}$ Grantham Research Institute on Climate Change and the Environment, The London School of Economics and Political Science \\ Floor 11, Tower 3, Clement's Inn, London, WC2A 2AZ, UK
}

\begin{abstract}
Flooding is recognised as one of the most common and costliest natural disasters in England. Flooding in urban areas during heavy rainfall is known as 'surface water flooding', considered to be the most likely cause of flood events and one of the greatest short-term climate risks for London. In this paper we present results from a novel Agent-Based Model designed to assess the interplay between different adaptation options, different agents, and the role of flood insurance and the flood insurance pool, Flood Re, in the context of climate change. The model illustrates how investment in adaptation options could reduce London's surface water flood risk, today and in the future. However, benefits can be outweighed by continued development in high risk areas and the effects of climate change. Flood Re is beneficial in its function to provide affordable insurance, even under climate change. However, it offers no additional benefits in terms of overall risk reduction, and will face increasing pressure due to rising surface water flood risk in the future. The modelling approach and findings are highly relevant for reviewing the proposed Flood Re scheme, as well as for wider discussions on the potential of insurance schemes, and broader multi-sectoral partnerships, to incentivise flood risk management in the UK and internationally.
\end{abstract}

\section{Introduction}

Flooding is the costliest natural disaster worldwide, and the effective management of long-term flood risk is an increasingly critical issue for many governments across the world, especially in light of climate change. In England flooding is recognised as one of the most common and costliest natural disasters and is listed as a major risk on the National Risk Register.

Flooding in urban areas during high intensity rainfall is termed 'surface water flooding'. This results from heavy rainfall which does not infiltrate the ground but ponds or flows overland before the runoff enters a natural or man-made drainage system or watercourse, or where water cannot enter a system as it is already at full capacity [1]. Surface water flooding occurs due to a complex interplay of factors, including the precise location, intensity and duration of rainfall, the characteristics of urban land surfaces and the engineering design of the surface drainage and sewer system.

The consequences of surface water flooding in the UK were dramatically demonstrated by the summer floods of 2007, which caused the country's largest peacetime emergency since World War II. The total economic cost of the floods was estimated to be $£ 3.2$ billion (2007 prices), with $£ 2.5$ billion borne by households at a cost of $£ 1.8$ billion to insurers [2]. These floods differed in scale and type from recent floods in

\footnotetext{
a Corresponding author: katie.jenkins@eci.ox.ac.uk
}

that a much higher proportion of flooding than normal came from surface water flooding rather than rivers.

The Pitt Review [3], conducted to provide lessons and recommendations in the aftermath of the 2007 summer floods, highlighted major gaps in the understanding and management of risks from surface water flooding. Similar concerns have also been raised across Europe with some member states giving a much lower priority to this type of flood risk in the past, meaning that vulnerability has crept upwards [4]. The Pitt Review also emphasised the need for urgent and fundamental changes in the way the UK is adapting to the likelihood of more frequent and intense

periods of heavy rainfall projected under future climate change [5]. Changing precipitation patterns are expected to result in an increase in surface water flood events in the UK [6]. Combined with an increasing pattern of urbanisation it has been estimated that damages from surface water flooding could increase by $60-220 \%$ over the next 50 years [7].

The combination of biophysical and human factors influencing surface water flood risk means that it is extremely challenging to predict the occurrence and extent of events, limiting the ability to warn and plan for future risks [8]. This and the large number of stakeholders involved (e.g. in the case of the UK and London see [9]) make managing surface water flooding a complex issue. One area where this is particularly 
apparent is flood insurance. While insurers traditionally insure against all types of flooding in the UK over the last decade the concerns about surface water flooding have contributed to a review of existing insurance practices.

A unique aspect of cross-sectoral involvement in flood management in the UK is the public-private partnership on flood insurance between the government and insurance industry known as the Statement of Principles (SoP). Flood insurance in England (and across the United Kingdom) is unique amongst most other national schemes as it is purely underwritten by the private market, while the government commits to flood risk management activities.

established in 2000 in the wake of growing

flood losses and sets commitments from both the insurance industry and government to establish flood insurance provision. The main obligations can be summarised as follows: flood insurance is provided by private insurers under the SoP to both households and small businesses, generally up to a risk level of a $1 / 75 \mathrm{yr}$ return period event, as part of their building and/or contents cover. Properties at higher risk are granted cover if insurers are informed by the Environment Agency (EA) about plans for flood defence improvements for that particular area within the next five years. Government commits to investment in flood defences and improved flood risk data provision as well as a strengthened planning system. Under this agreement, the emphasis on flood risk reduction is primarily placed on the government (national and local) while insurers provide the financial underwriting.

Following the 2007 UK summer floods a review of the SoP was triggered, with a renewed version being put in place from 2009 until June 2013. After more than two years of negotiation a modified version of the partnership was agreed in 2013 resulting in the creation of Flood Re, a new pool solution for high-risk properties commencing in April 2016. Households under low to normal flood risk will still be provided with insurance as standard, whilst the flood element of the home insurance policy for the 1$2 \%$ of highest risk properties can be passed to Flood Re by insurers. The premiums offered for high risk households are fixed dependent on council tax banding. Flood Re will be funded by these premiums, and an annual levy taken from all policyholders and imposed on insurers according to their market share [10].

The proposed Flood Re scheme is designed by Government and industry as a transitional solution, with an anticipated run time of 25 years. It aims to help smooth the transition to more risk-based pricing in a competitive insurance market in the future while securing future affordability and availability of flood insurance [11].

While the change in the flood insurance scheme has been triggered by concerns about the rising flood losses it remains unclear if and how Flood Re will be able to cope with future risks and fulfil its tasks. While the recent flood loss trends in the UK are largely due to socioeconomic factors, such as more development in exposed areas, climate change is expected to exacerbate these impacts [5]. Therefore, one important aspect is if and how insurance can be integrated into overall risk management and climate change adaptation efforts.

Concerns have also been raised over the financial sustainability of Flood Re given that costs will remain higher than benefits delivered [11, p.30]; as climate change has not been incorporated into the Flood Re risk modelling despite its 25 year outlook [10]; as Flood Re was not designed with risk reduction in mind and offers no incentives or formal mechanisms to encourage household level flood risk reduction [10]; and as implications of the scheme, and potential negative and positive feedbacks, have not been considered in parallel with other flood risk management interventions, including those targeted at surface water flooding.

These gaps formed the starting part of our investigation. Analysing the outcomes of such an insurance reform and its potential integration with flood risk management and climate change requires a model that can simulate the dynamics of flooding, changing levels of risk, and the choices made by different stakeholders. We present an Agent-Based Model (ABM) developed for Greater London and applied here to a case study of the London Borough of Camden, an area at high risk of surface water flooding. The model is used to assess the interplay between different adaptation options; how risk reduction could be achieved or incentivised by different agents; and the role of flood insurance and Flood Re, all in the context of climate change.

\section{Study area}

Floods are a major issue for London as it is vulnerable to tidal, fluvial, surface water, sewer and groundwater flooding. Surface water flooding is considered to be the most likely cause of flood events in London, and one of the greatest short-term climate risks [12]. Around 680,000 properties are estimated to be at risk with 140,000 Londoners at high risk, and another 230,000 at medium risk [13]. The number of residential properties prone to surface water flooding has been increasing from 2001 to 2011 , as has the proportion of urban land covered with manmade surfaces [14].

The London Borough of Camden (Figure 1) encompasses an area of $21.8 \mathrm{~km}^{2}$ and a population of approximately 228,400 people [15]. Surface water flooding poses a large risk to Camden due to the nature of summer thunderstorms and the topography of the area, with a historic precedent for such events [16]. The area is not at risk of flooding from the River Thames or any other open rivers. 

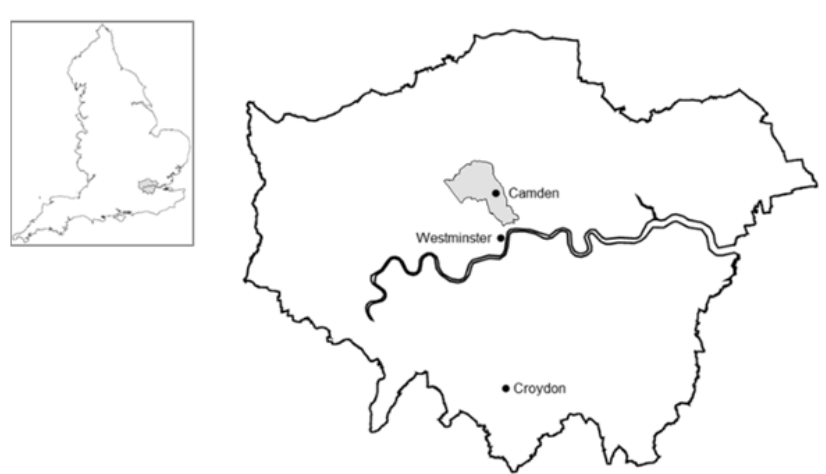

Figure 1: The boundary of Greater London, the London Borough of Camden and the location in England (inset)

\section{The Agent-Based Model}

ABMs provide a bottom-up approach for understanding dynamic interactions between different agents in complex systems. They are advantageous for visualising the effects of changing behaviours and emergent properties of complex adaptive systems. They have a number of advantages as a support tool for policy making such as their flexibility for testing different conditions and behavioural rules [17].

The ABM includes six different agents: people, houses, an insurer, a bank, a developer and a local government, each with their own behaviour. Table 1 summarizes the main agent behaviours which underlie the model (see $[9,18]$ for further model details).

The methodological approach and design of the $\mathrm{ABM}$ are novel in four key respects. Firstly, the ABM allows different combinations of surface water flood risk management options to be modelled, to include structural adaptation options, the role of insurance, and the specific case of Flood Re. Secondly, the model is dynamic in nature. In contrast, flood risk has typically been calculated using static data on properties at risk and the damage that will occur during a flood [19]. Unlike the approach presented here this does not address the distribution of losses across different households and the role of adaptation options or insurance in redistributing those losses. Nor does it address the dynamics of householders' choices, and how these may be modified by flood risk and insurance availability [20].
Thirdly, the design of the ABM is advanced in that it links behavioural and physical components. It incorporates a surface water flood event dataset for present and future climate scenarios, developed by combining probabilistic precipitation projections with detailed surface water flood depth maps [21]. In contrast, climate change is normally

accounted for in studies of surface water flood risk by increasing rainfall intensity by a specific uplift rate (e.g. [22]). In justifying this approach Defra [23] note there is no standard methodology for determining the impact that climate change will have on surface water flooding. Besides limitations of focusing on a single climate response within management plans, this approach doesn't facilitate quantification of uncertainties for governments and policy makers to support the design and implementation of robust and economical adaptation options.

Finally, the ABM is GIS explicit to allow a realistic spatial representation of the built environment, socioeconomic characteristics, and surface water flood risk.

The ABM was developed firstly test the role of Flood $\mathrm{Re}$ and different structural adaptation options in managing surface water flood risk, individually and in combination. In the model the local government aims to reduce flood risk by investing in surface water flood reduction projects in the form of sustainable drainage systems (SUDS) and the provision of grants for propertylevel protection measures (PLPMs).

Each experiment setting was run using surface water flood event time series data for the baseline (19611990) and future high emission climate change scenarios for the 2030s $(2030 \mathrm{H})$ and $2050 \mathrm{~s}(2050 \mathrm{H})$. The experiments were run at a yearly time-step for 100 simulations of the 30 -year time series data corresponding to the baseline, $2030 \mathrm{~s}$ and $2050 \mathrm{~s}$ so as to sample stochastic variability in the rainfall series. These repeated simulations are each driven by a new resampling of the uncertainties in the climate scenarios, so the statistical results also reflect these uncertainties. In the experiments it is assumed that Flood Re is operational over 30 years. Testing of different mechanisms for the transition to risk based pricing are not presented in this paper. 


\begin{tabular}{|c|c|}
\hline Agent & Main Behaviours \\
\hline Homeowner & $\begin{array}{l}\text { Decide to buy or sell properties } \\
\text { Required to renew flood insurance annually } \\
\text { Pay household fees } \\
\text { Decide whether to invest in PLPMs (assumed that } 1 \% \text { of homeowners invest proactively per year, while } 34 \% \text { invest reactively } \\
\text { following a flood) } \\
\text { May consider flood risk when considering to purchase a new property }\end{array}$ \\
\hline Insurer & $\begin{array}{l}\text { Estimates household surface water flood risk for every property in model (it is assumed that where in place they account for } \\
\text { PLPMs and SUDs in these estimates) } \\
\text { Sets insurance premiums and excess levels for every property in model } \\
\text { Provides all households with flood insurance } \\
\text { Decide whether it is cost effective to place high risk properties into Flood Re } \\
\text { Provide compensation, minus the excess, to properties following a flood event }\end{array}$ \\
\hline $\begin{array}{l}\text { Local } \\
\text { Government }\end{array}$ & $\begin{array}{l}\text { Invest up to } 80 \% \text { of their local flood defence budget (or more in the year of a flood event) in SUDS projects which protect } \\
\text { houses at highest risk of flooding and provide a cost-benefit ratio of } 1: 5 \text { or greater } \\
\text { Invest up to } 20 \% \text { of their local flood defence budget to provide } £ 5000 \text { grants to households investing in PLPMs } \\
\text { Evaluate and approve/reject property development plans based on their financial benefits and flood risk } \\
\text { Sell land to developers for approved property developments }\end{array}$ \\
\hline Developer & $\begin{array}{l}\text { If demand for new properties outstrips available properties on the market propose to build new properties to meet demand } \\
\text { Identify optimal land to maximise profits from developments, within allocated development areas and the local governments } \\
\text { planned development trajectory } \\
\text { Submit development proposal to be approved by the local government } \\
\text { Build new houses (initially assumed that } 50 \% \text { of all houses built will have SUDS) and sell on the market }\end{array}$ \\
\hline Bank & $\begin{array}{l}\text { Reposes houses if the owners are unable to afford household fees for three consecutive years } \\
\text { Sell houses on market }\end{array}$ \\
\hline
\end{tabular}

Table 1: Summary table of main agent behaviours

\section{Results}

The simulation results presented below are reflective of the modelled trends seen in the surface water flood event data set of Jenkins et al., [21], which highlighted that for Greater London the frequency of surface water flood events exceeding present day $1 / 30 \mathrm{yr}$ return levels increased by $53 \%$ under the $2050 \mathrm{H}$ climate change scenario.

Figure 2 highlights how the level of risk to properties also changes over time (assuming the present day insurance mechanism is in place and there is no additional investment in flood protection measures), and provides a baseline case on which to compare the experiments. The points reflect the annual results for each of the 100 model runs for each climate scenario (and illustrate an increase in variability between the runs over time), with a smoothed line of best fit. The key driver of the upward trend in surface water flood risk is the development of new properties, often in areas of high flood risk, which drives up the overall flood risk of the area. Comparing across the climate scenarios the average surface water flood risk of properties increases, by up to $80 \%$ by year 30 in the $2050 \mathrm{H}$ scenario.

The ABM was used to test the role of different structural adaptation options and insurance for influencing surface water flood risk levels. The below results illustrate the upper and lower bounds of the different options modelled, and potential benefits and limitations of different combinations of options. For the baseline climate scenario Figure 3 highlights how the implementation of PLPMs (experiment 4) or SUDS (experiment 3) reduce the trend in the average surface water flood risk of houses over time, by around $10 \%$ and $15 \%$ respectively by year 30 . The effectiveness of investment in SUDS and PLPMs are initially very similar even though installation of SUDS is assumed to reduce the potential flood damage by $35 \%$, whilst installation of PLPMs are assumed to reduce the potential flood damage by $75 \%$. And secondly, given that annually a larger number of properties are protected by PLPMs than SUDS in the model. This reflects the rationale of the local government in the model to build surface water flood defence projects in the areas at highest risk of surface water flooding where the economic benefits and level of risk reduction will be the greatest (Figure 4). This is compared to people who are assumed to invest in PLPMs in a less rational manner in the model, reflecting broader anxiety and emotions [24].

Figure 3 also highlights that the greatest benefits in terms of reduced risk are seen under experiments 7 and 8 where investments are made in both SUDS and PLPMs, with a $23 \%$ decline by year 30 compared to experiment 1 for all three climate scenarios. The experiments which include Flood $\mathrm{Re}$ suggests that this scheme has no additional benefit in terms of overall risk reduction. In fact, in the $2030 \mathrm{H}$ and $2050 \mathrm{H}$ climate scenarios the opposite effect is seen with slightly higher levels of overall flood risk emerging by year 30 . This trend is an indirect result of the positive effects of Flood Re seen on the broader housing market in terms of house prices and the number of mortgage foreclosures [9]. After several years of growing house sales the related increase in house prices means that home buyers start to search for different more affordable options, at which point the developer addresses this demand by developing more properties. Consequently, as house prices rise so does the investment in new developments, often in areas of high flood risk, and subsequently overall flood risk increases in the model [9]. 


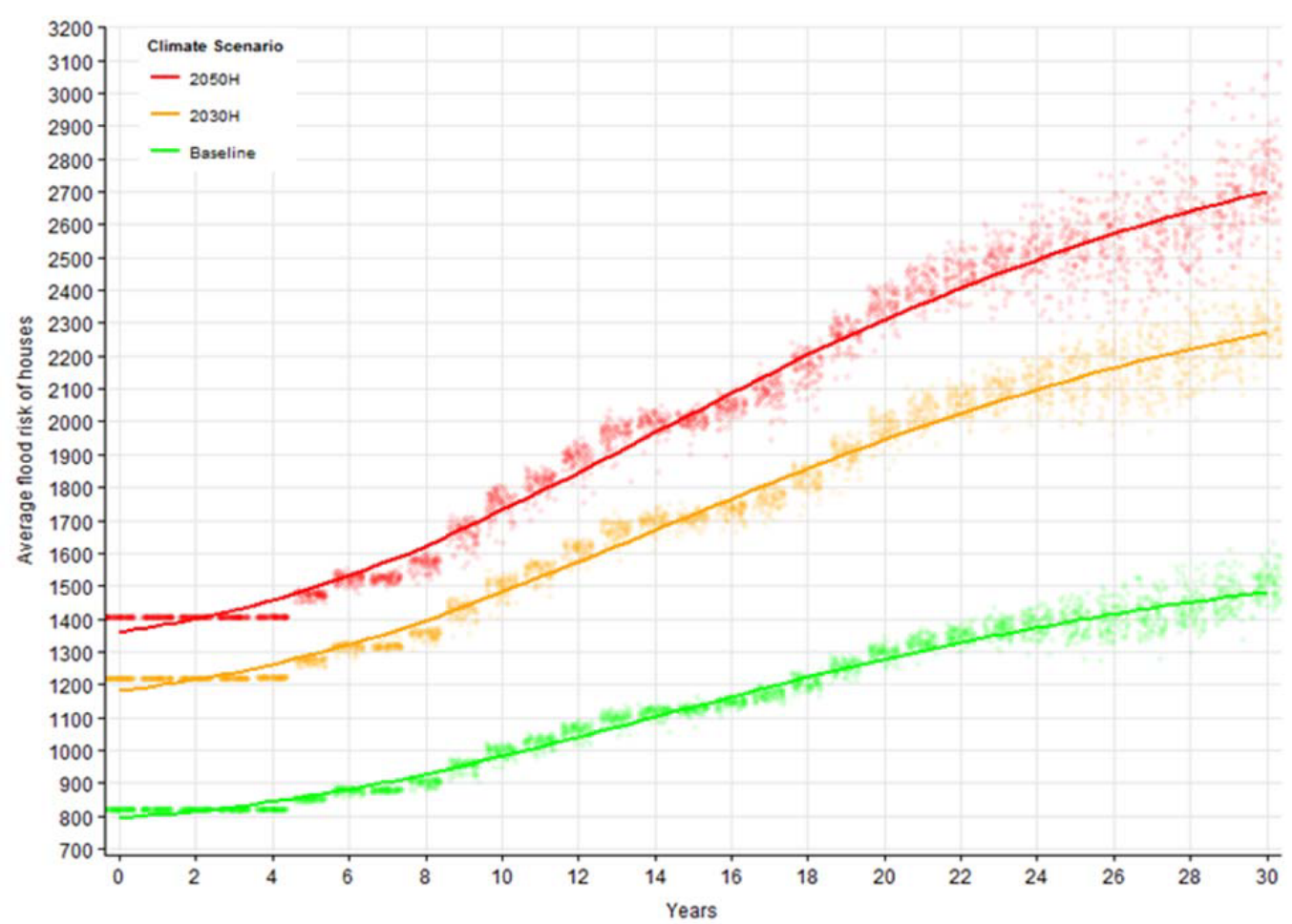

Figure 2: The average annual flood risk of houses susceptible to surface water flooding.



Figure 3: The average surface water flood risk calculated for each of the experiments under the baseline, $2030 \mathrm{H}$ and $2050 \mathrm{H}$ climate scenarios. 


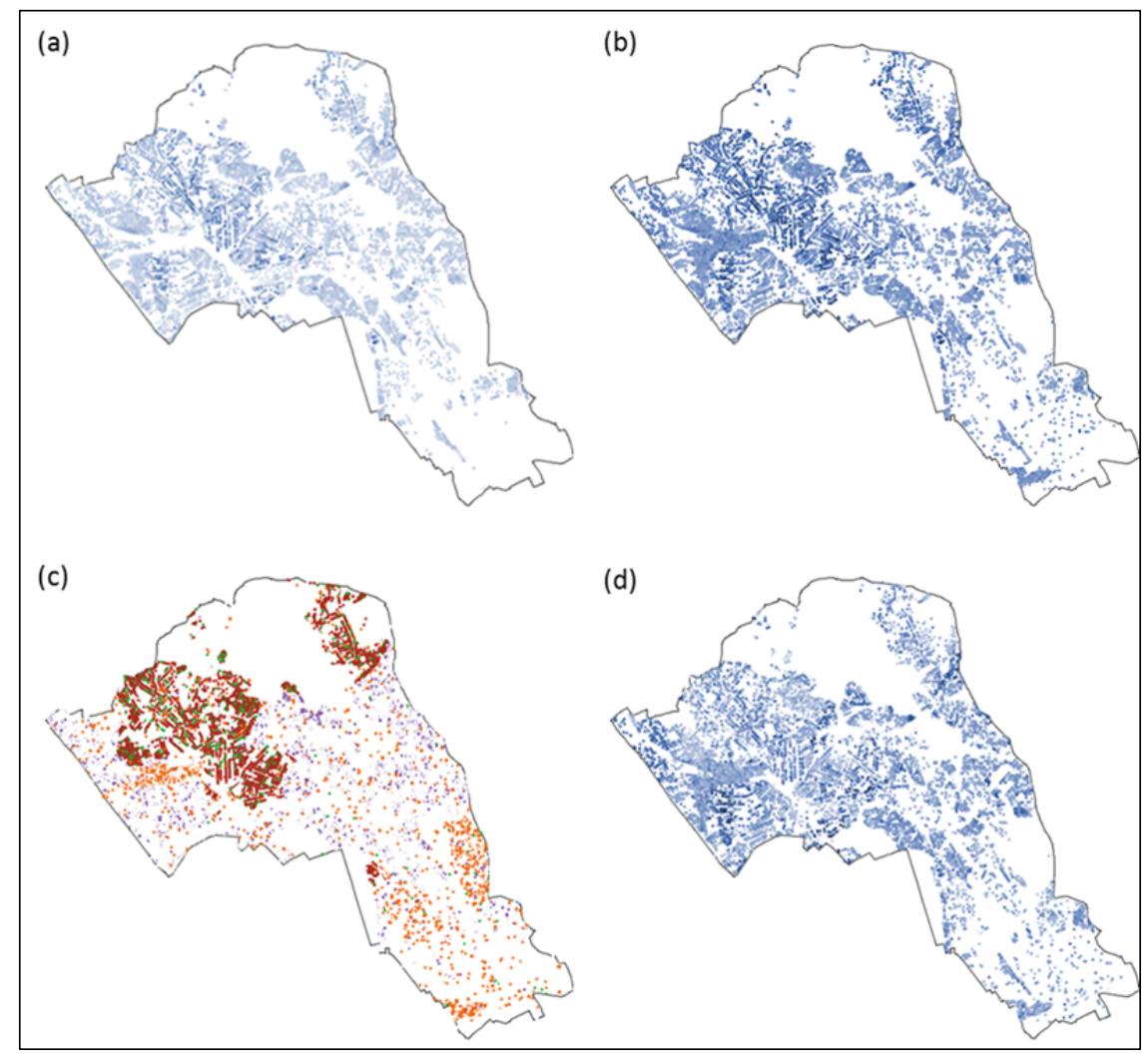

Figure 4: Image (a) shows the initial modelled surface water flood risk to houses in Camden at the start of a single model run for the $2050 \mathrm{H}$ climate scenario (darker blue indicates higher flood risk); (b) shows the modelled surface water flood risk in year 30 under experiment 1. In comparison, (c) shows the spatial pattern of investment in flood protection (red reflects investments in SUDS by the local government; purple shows PLPM investments; and green reflects properties that have both) under experiment 7; (d) highlights the related level of surface water flood risk for experiment 7

Figure 3 also highlights how average household surface water flood risk continues to increase over time, regardless of investment in risk reduction measures. This is due to the continued development of properties in flood risk areas. While more stringent controls on the developer would reduce this risk it highlights the real pressure local governments are put under by central government to develop more houses, and the trade-offs which must be made when addressing flood risk and housing shortages.

The results also highlight the role of climate change in driving surface water flood risk. Even in the best cases (experiments 7 and 8) where there is combined investment in flood risk management options the level of risk continues to increases above the worst case baseline scenario, being $13 \%$ higher under the $2030 \mathrm{H}$ scenario and $33 \%$ higher under the $2050 \mathrm{H}$ scenario. This highlights the imperative to design surface water flood risk management strategies with climate change and future levels of risk in mind if impacts and costs are to stay at or below present levels.

Figure 5 highlights that Flood Re does achieve its purpose of keeping insurance premiums affordable for high risk properties. Under the baseline climate scenario household flood premiums initially remain below the thresholds where it would become economical to pass properties into Flood $\mathrm{Re}$, and as such this has limited effect on average flood premiums in the first 8 years. However, as premiums increase (reflecting the increased risk highlighted in Figure 3), the potential benefits of PLPMs and SUDS for risk reduction and premiums are emphasised. The inclusion of Flood Re further reduces average premiums, from approximately $£ 650$ to $£ 280$ in the baseline scenario. Even under future climate change scenarios average premiums are limited to $£ 450-£ 550$ by year 30 , with a clear divergence in results which include/exclude Flood Re. The experiments without Flood Re illustrate much higher and steeper increases in average flood insurance premiums, upwards to $£ 1700$ under the 2050 high scenario. An interesting observation is that investment in SUDS or a combination of SUDS and PLPMs helps stabilise insurance premiums over time - a clear indicator that surface water risk management is essential to maintain the viability of flood insurance.Importantly, Flood Re has been designed to be a transitional solution with an anticipated life of 25 years, over which time the scheme will transition to more riskbased pricing in a competitive insurance market. A key issue is how the scheme will cope with the increasing gap between subsidised and risk based premiums given urbanisation and climate change. The potential gap is highlighted through the comparison of experiments with and without Flood Re, with increasing divergence over time and across the climate scenarios.

Furthermore, while our simulations indicate that Flood Re could ensure the affordability of insurance to homeowners, even under future climate change, this is modelled here without constraint on the number of properties which can be placed into Flood Re. An extension of Flood $\mathrm{Re}$ could have significant consequences for its funds and reinsurance cover, with 
affordable cover becoming harder to sustain under the future scenarios.

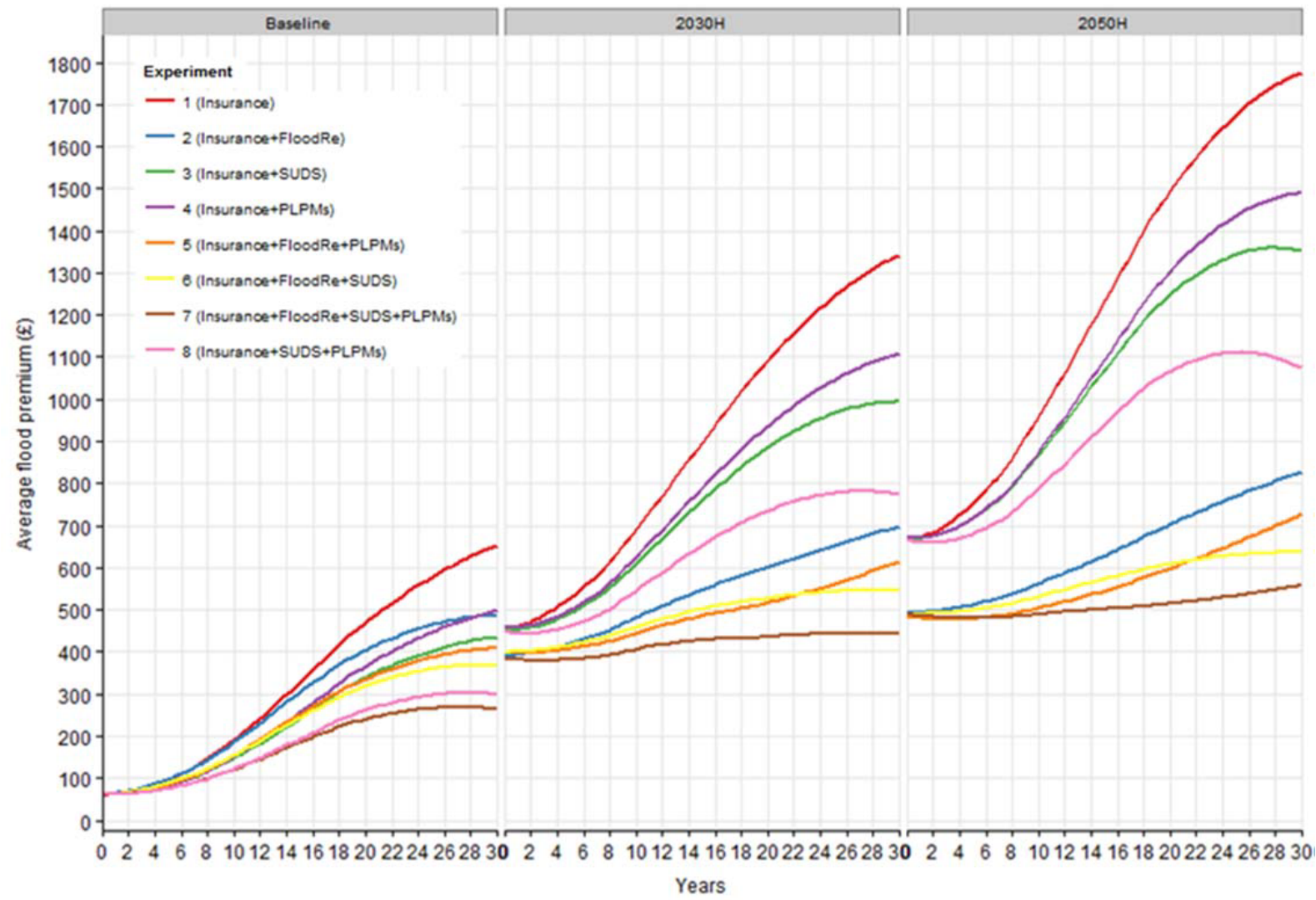

Figure 5: Average flood premiums of houses in risk for each of the experiments under different climate scenarios

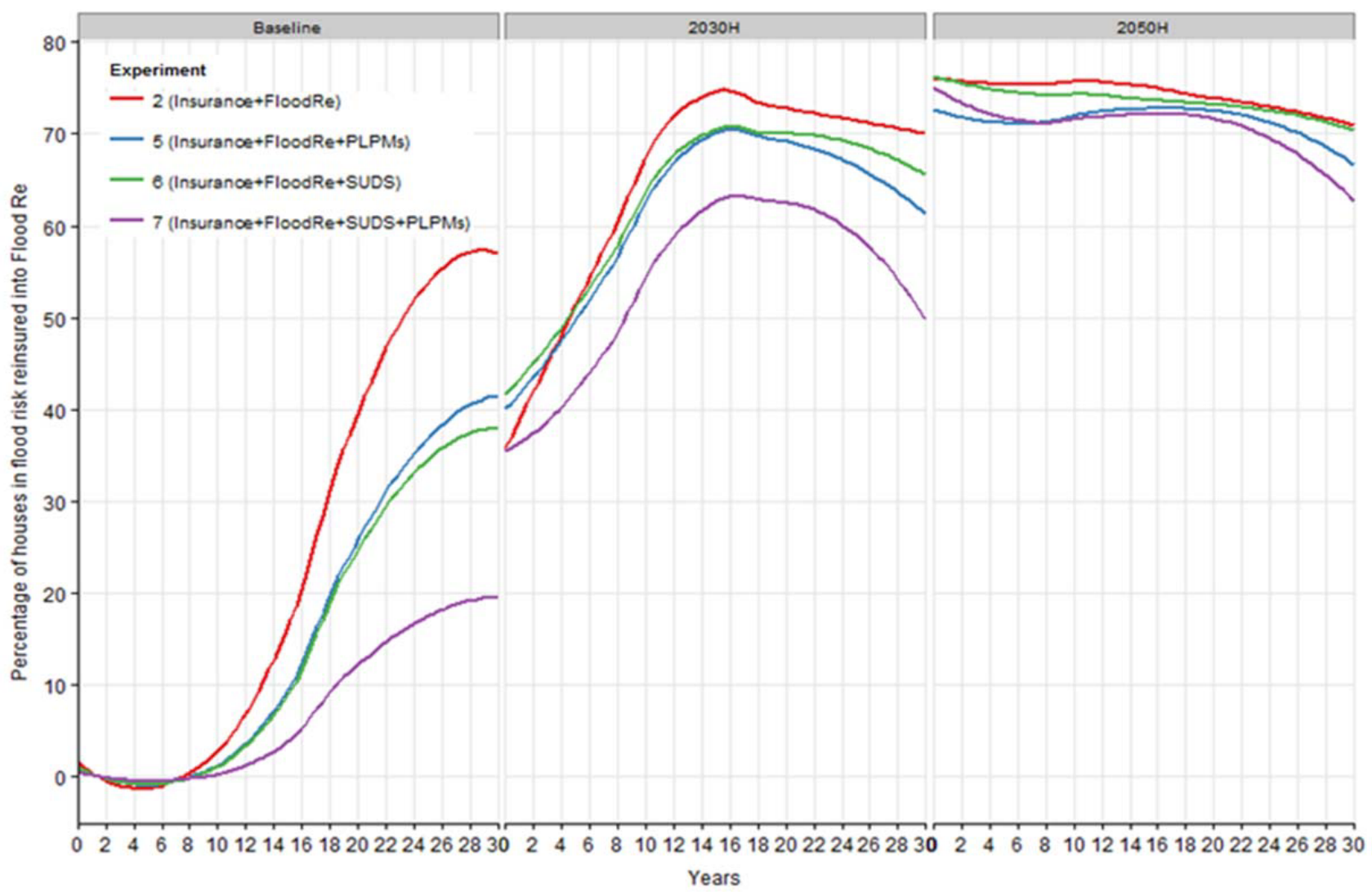

Figure 6: The percentage of properties at risk of surface water flooding reinsured into Flood Re 
Figure 6 demonstrates that in the baseline scenario there is initially limited demand for Flood Re. Coinciding with the rise in surface water flood risk and premiums in the study area there is a sharp increase in properties placed in the scheme from around year 8, ranging from $20-58 \%$. However, under the future climate scenarios $40-$ $75 \%$ of properties are immediately ceded to Flood Re (based on their surface water flood history). The declining trend seen towards the end of the 30-year period reflects the increasing proportion of new build houses in flood risk which are not eligible for inclusion in Flood Re.

Finally, while Flood Re does not directly incentivise investment in PLPMs or SUDS a positive feedback is seen in the model in that fewer properties are re-insured into Flood $\mathrm{Re}$ when these measures are in place. This is as PLPMs and/or SUDS are accounted for when estimating the potential damage to properties affected by flooding, and consequently lowers the insurers estimate of flood risk of protected properties and in some cases the need to place the property into Flood Re. In these simulations a combination of insurance, SUDS, and PLPMs are shown to be most beneficial in terms of reducing the number of properties which are placed into Flood Re.

\section{Discussion}

The paper outlines an ABM developed to model the dynamics of surface water flooding, changing surface water flood risk, and how adaptation and insurance decisions could affect future surface water flood risk in that dynamic. While the focus of this paper is a case study of Camden the modelling approach is applicable to the broader situation in Greater London. It could also be extended to other areas in the UK or specific situations in other countries (dependent on availability of relevant data and computational resources). The analysis is novel due to its dynamic nature and as different combinations of surface water flood risk management options can be modelled, including structural adaptation options, insurance, and the specific case of Flood Re.

Filatova [25] highlights the need to move from conceptual modelling experiments to simulating real life situations through the use of available data if an ABM is to be applied for policy analysis and be seen as robust by relevant stakeholders. In this example, the model has been parameterised based on a large array of data sources, developed around GIS data to allow a realistic representation of residential buildings and surface water flood risk, and repeated simulations carried out to provide an assessment of uncertainty.

However, a limitation of this design is that the ABM inevitability becomes more complex and as with all models the results must be carefully interpreted given the underlying assumptions which are necessary given this complexity. For example, in the version presented it is assumed that SUDS and PLPMs do not fully mitigate flood risk but reduce damage homogenously across the study area; there are no constraints on the number of properties ceded into Flood Re or the available assets of the scheme; and certain behaviours such as how insurers account for investment in SUDs and PLPMs are simplified.

Still, the ability of the framework to incorporate different agents with their own behaviours; flexibility for testing different conditions and behavioural rules; flexibility to test and evaluate different policies and options; and the ability to visualise and quantify this in a spatial and dynamic manner, highlights the potential of such a modelling approach to support and inform decision making.

The ABM has highlighted how climate change and socio-economic development can exacerbate current levels of surface water flood risk in Camden. Surface water flood risk also increases over time under each climate scenario, reflecting the continued development of properties in areas of flood risk in the model. The most beneficial result for surface water flood risk reduction was a combination of investment in both PLPMs and SUDS. This highlights the need for further investment and provision of grants for PLPMS and adds support to the current reviews and government led pilot schemes being undertaken in the UK. However, in our model even with SUDS and PLPMs in place the average surface water flood risk continued to increase over time, and under no experiment did it stabilise or decline. Given the implications of climate change on surface water flood risk this illustrates the danger of further trade-offs between future development plans and flood risk management.

The ABM shows that Flood Re would achieve its aim of securing affordable flood insurance premiums. However, findings also highlight that Flood Re would be placed under increased strain if challenged with increasing flood risk under future climate change. Several of the questions addressed in our analysis also have particular relevance for Flood Re's transition process, which will determine if and how the new scheme operates over time. A key issue will be how the increasing gap between the level of premiums paid by high risk properties and the risk based value they would face outside this scheme is addressed and managed over time.

The ABM is beneficial in that it provides a framework to further investigate the transitional mechanisms recently proposed as part of the Flood Re scheme [26], as well as how changes to regulatory measures and the roles and behaviour of different stakeholders could be enhanced to support surface water flood risk reduction under future climate change [27]. This is important as in our model Flood Re is shown to have no additional benefits in terms of overall risk reduction. This supports concerns that the new scheme is missing an opportunity to contribute to risk reduction, which is important to its own resilience under future climate change. It also raises concerns about issues of moral hazard as it could de-incentivise flood risk reduction at a household level and dissuade homeowners from investing in PLPMs while in place [10]. This is a key design issue for Flood $\mathrm{Re}$ as in its current format there is no remit and no funding to foster such a resilience-enhancing role. 


\section{Conclusions}

Whilst there is extensive literature on fluvial and coastal flood risk, surface water flood risk has received less attention both nationally and internationally. For example, in the UK there are still major gaps in the understanding and management of risks from surface water flooding, and the need for fundamental changes in how we adapt to such challenges in the future. The number of stakeholders involved, and varying degrees of responsibility across government and other agents, further complicates the ability to manage risk in an integrated manner. The example of flood insurance highlights this. One the one hand there is the (political) quest to keep flood insurance affordable, while improved risk data and a growing recognition of the challenge of surface water flooding suggest that the technical price of insurance should be rising. This then requires some form of subsidy, either indirect as seen under the SoP arrangement, or direct, as proposed through Flood Re, to make insurance more economical for those at higher risk.

Our particular interest in the interactions between flood insurance in the UK and surface water flood risk management stems from the current changes facing the industry with the introduction of the Flood Re pool in April 2016. However, efforts to reform the insurance arrangements have predominantly focused on dealing with the affordability of insurance without considering the implications of alternative mechanisms for managing and reducing the underlying risks. Reflecting on evidence emerging from other European and international flood insurance schemes, we notice that this is not an exception but rather the norm [10]. Yet, depending on its design and implementation an insurance scheme can send signals to policy makers in support of flood risk management policies, which would address risk levels. For example through changes to the planning system and building regulations. Our study finds that the new Flood $\mathrm{Re}$ scheme does not enhance this policy link nor the incentivisation of home resilience, which is a missed opportunity.

Until now this issue has not received sufficient attention due to a lack of data and analysis. The ABM and results presented here reflects on current policy in terms of planning, national and local adaptation, and flood risk management. It highlights that there is still discord between these. The potential of integrating these options and using Flood Re along with other measures such as grants for PLPMs and enhanced planning policy can be investigated through the ABM and results quantified to account for the role of different actors, changing risk under future climate change, and potential uncertainties.

Our findings directly feed into the question of transition planning, which is a fundamental pillar of Flood Re. This analysis suggests further policy on planning developments, increased investment in SUDS for new and existing properties, and investment in PLPMS is required. The forthcoming Flood Re scheme could help with this transition if it were able to incentivise such measures. These issues are likely to become more apparent under climate change and urbanisation and need to be considered within the framework if areas like Camden are to become more resilient to surface water flood events in the future.

\section{Acknowledgements}

This research was undertaken as part of the ENHANCE Project (Enhancing risk management partnerships for catastrophic natural hazards in Europe), funded under the Seventh Framework Programme of the European Union under grant agreement No 308438.

The authors would like to acknowledge the financial support of the UK Economic and Social Research Council (ESRC) through the Centre for Climate Change Economics and Policy and the use of the University of Oxford Advanced Research Computing (ARC) facility in carrying out this research (http://dx.doi.org/10.5281/zenodo.22558).

\section{References}

1. Falconer, R. H., Cobby, D., Smyth, P., Astle, G., Dent, J., and Golding, B. (2009). Pluvial flooding: new approaches in flood warning, mapping and risk management. Journal of Flood Risk Management, 2(3), 198-208.

2. Environment Agency. (2010). The costs of the summer 2007 floods in England. Environment Agency, Bristol.

3. Pitt, M. (2008). Learning Lessons from the 2007 Floods, The Pitt Review. Cabinet Office, London.

4. European Water Association. (2009). EWA Expert Meeting on Pluvial Flooding in Europe, Final Report. EWA, Brussels, Belgium.

5. IPCC (Ed.). (2013). Summary for Policymakers. In: Climate Change 2013: The Physical Science Basis. Contribution of Working Group I to the Fifth Assessment Report of the Intergovernmental Panel on Climate Change (Vol. 1). Cambridge University Press, Cambridge.

6. Ramsbottom, D., Sayers, P. and Panzeri, M. (2012). Climate Change Risk Assessment for the Floods and Coastal Erosion Sector. UK Climate Change Risk Assessment. Defra, London.

7. Adaptation Sub-Committee. (2012). Climate Change - Is the UK preparing for flooding and water scarcity? Committee on Climate Change, London.

8. Houston, D., Werritty, A., Bassett, D., Geddes, A., Hoolachan, A., and McMillan, M. (2011). Pluvial (rain-related) flooding in urban areas: the invisible hazard. Joseph Rowntree Foundation.

9. Jenkins, K., Surminski, S., Hall, J., and Crick, F. (2016). Assessing surface water flood risk and management strategies under future climate change: an agent-based model approach. Centre for Climate Change Economics and Policy Working Paper No.252; Grantham Research Institute on Climate Change and the Environment Working Paper No.223.

10. Surminski, S. and Eldridge, J. (2015). Flood insurance in England - an assessment of the current 
and newly proposed insurance scheme in the context of rising flood risk. Journal of Flood Risk Management. DOI: $10.1111 /$ jfr3.12127.

11. Defra. (2013). Securing the future availability and affordability of home insurance in areas of flood risk. Defra, London.

12. Greater London Authority. (2011). The London Climate Change Adaptation Strategy. GLA, London.

13. Greater London Authority. (2014). Flood risks in London: Summary of findings. GLA, London.

14. HR Wallingford. (2012). Development of spatial indicators to monitor changes in exposure and vulnerability to flooding and the uptake of adaptation actions to manage flood risk in England: Results 2012. HR Wallingford Ltd, Oxfordshire.

15. Greater London Authority. (2015). London datastore http://data.london.gov.uk/. GLA, London.

16. Drain London. (2011). Surface Water Management Plan: London Borough of Camden. Camden Council.

17. van Dam, K.H., Nikolic, I. and Lukszo, Z. (2012). Agent-based modelling of socio-technical systems. Springer Netherlands, p. 268.

18. Dubbelboer, J., Nikolic, I., Jenkins, K. and Hall, J. (2016). An Agent-Based Model of Flood Risk and Insurance. Journal of Artificial Societies and Social Simulation, In Review.

19. Hall, J.W., Dawson, R.J., Sayers, P.B., Rosu, C., Chatterton, J.B. and Deakin, R. (2003). A methodology for national-scale flood risk assessment. Water \& Maritime Engineering 156, 235-247.

20. Dawson, R.J., Ball, T., Werritty, J., Werritty, A., Hall, J.W. and Roche, N. (2011). Assessing the effectiveness of non-structural flood management measures in the Thames Estuary under conditions of socio-economic and environmental change. Global Environmental Change 21, 628-646.

21. Jenkins, K., Hall, J., Glenis, V. and Kilsby, C. (2016). A probabilistic analysis of surface water flood risk and management options in Greater London. Journal of Risk Analysis. In Review.

22. Sayers, P.B., Horritt, M., Penning-Rowsell, E., and McKenzie, A. (2015). Climate Change Risk Assessment 2017: Projections of future flood risk in the UK. Research undertaken by Sayers and Partners on behalf of the Committee on Climate Change. Committee on Climate Change, London.

23. Defra. (2011). Commencement of the Flood and Water Management Act 2010, Schedule 3 for Sustainable Drainage: Impact Assessment. Defra, London.

24. Harries, T. (2012). The anticipated emotional consequences of adaptive behaviour - impacts on the take-up of household flood-protection measures. Environment and Planning A, 44(3), 649-668.

25. Filatova, T. (2015). Empirical agent-based land market: Integrating adaptive economic behavior in urban land-use models. Computers, Environment and Urban Systems 54, 397-413.

26. Flood Re. (2016). Transitioning to an affordable market for household flood insurance: The first
Flood Re transition plan. Flood Re, London. February 2016.

27. Surminski, S., Jenkins, K. and Crick, F. (2015). London Case Study: Flood risk and climate change implications for MSPs. ENHANCE deliverable 7.4: Assessment of multi-sectoral partnerships. www.enhanceproject.eu. 